\title{
Faktor-Faktor yang Mempengaruhi Nilai Perusahaan pada Perusahaan Manufaktur Sektor Industri Barang Konsumsi yang Terdaftar di BEI Periode 2016-2018
}

\author{
Pratiwi Pardiastuti \\ Universitas Islam Batik (UNIBA) Surakarta \\ pratiwidias87@gmail.com
}

\author{
Yuli Chomsatu Samrotun \\ Universitas Islam Batik (UNIBA) Surakarta \\ chom satoe@gmail.com
}

\author{
Rosa Nikmatul Fajri \\ Universitas Islam Batik (UNIBA) Surakarta \\ rosanikmatulfajri@mail.ugm.ac.id
}

Corresponding Author: Pratiwi Pardiastuti

Submitted: 7 Januari 2020

Accepted: 1 Agustus 2020

Published: 1 Agustus 2020

\section{Abstract}

This study aims to analyze the factors that influence value company (PBV) which includes dividend policy (DPR), company size (SIZE), capital structure (DER), liquidity (CR), and profitability (ROA). The population in this study is a manufacturing company in the consumer goods industry sector listed on Indonesia Stock Exchange (IDX) for the period 2016-2018. The sampling technique uses the method purposive sampling, so we obtained a sample of 18 companies. Type quantitative research. Data sources in the form of secondary data. Data analysis used is multiple linear regression analysis. The results showed that partially dividend policy (DPR), capital structure (DER) and profitability (ROA) affect on value company $(P B V)$. While the size of the company (SIZE) and liquidity $(C R)$ has no affect on value company $(P B V)$.

Keywords : Dividend Policy, Company Size, Capital Structure, Liquidity, Profitability, Value Company

\section{PENDAHULUAN}

Pada era globalisasi saat ini perkembangan dunia bisnis di Indonesia mengalami kemajuan yang sangat pesat. Banyaknya perusahaan yang berkembang di segala bidang usaha, mengakibatkan persaingan di dunia bisnis menjadi semakin kuat. Dengan persaingan tersebut setiap perusahaan akan termotivasi dan berlomba-lomba untuk mengoptimalkan kinerjanya agar mampu mencapai tujuan perusahaan. Tujuan utama perusahaan salah satunya adalah meningkatkan nilai perusahaan (Sudana, 2011). Nilai perusahaan penting untuk diperhatikan karena tingginya nilai perusahaan akan meningkatkan kemakmuran pemegang saham (Brigham \& Houston, 2010).

Bagi perusahaan yang telah go public, nilai perusahaan tercermin dalam harga sahamnya, harga saham yang tinggi 
dapat meningkatkan kepercayaan investor untuk menginvestasikan dananya, serta dapat mencerminkan kinerja keuangan perusahaan. Semakin baik kinerja perusahaan semakin tinggi pula nilai perusahaan. Nilai perusahaaan dapat dipengaruhi oleh banyak faktor. Dalam penelitian ini beberapa faktor yang dapat mempengaruhi nilai perusahaan, diantaranya: kebijakan dividen, ukuran perusahaan, struktur modal, likuiditas, dan profitabilitas.

Beberapa penelitian terdahulu yang melatarbelakangi penelitian ini antara lain penelitian (Wijoyo, 2018) membuktikan nilai perusahaan tidak dipengaruhi oleh kebijakan dividen, namun hasil berbeda ditunjukkan oleh (Putra \& Lestari, 2016) dan (Umam \& Hartono, 2019) yang menyatakan bahwa kebijakan dividen bepengaruh terhadap nilai perusahaan.

Penelitian yang dilakukan oleh (Lumoly, Murni, \& Untu, 2018) dan (Suryandani, 2018) menyatakan hasil bahwa nilai perusahaan tidak dipengaruhi oleh ukuran perusahaan, namun hasil penelitian tersebut tidak sejalan dengan penelitian (Putra \& Lestari, 2016) dan (Novari \& Lestari, 2016) yang menyatakan ukuran perusahaan mempengaruhi nilai perusahaan.

Penelitian lain oleh (Dhani \& Utama, 2017) menyatakan hasil bahwa nilai perusahaan tidak dipengaruhi oleh struktur modal, namun hasil berbeda ditunjukkan oleh (Gunawan, Pituringsih, \& Widyastuti, 2018) yang menyebutkan hasil bahwa nilai perusahaan dipengaruhi oleh struktur modal.

Penelitian oleh (Lumoly, Murni, \& Untu, 2018) dan (Chasanah, 2018) menunjukkan hasil nilai perusahaan tidak dipengaruhi oleh likuiditas, namun hasil berbeda ditunjukkan oleh (Andriani \& Rudianto, 2019) yang menyebutkan hasil bahwa nilai perusahaan dipengaruhi oleh likuiditas.

Penelitian lain oleh (Warouw, Nangoy, \& Saerang, 2016) menyatakan hasil profitabilitas tidak berpengaruh terhadap nilai perusahaan, namun hasil berbeda ditunjukkan oleh (Lumoly, Murni, \& Untu, 2018) dan (Umam \& Hartono, 2019) menyatakan hasil bahwa nilai perusahaan dipengaruhi oleh profitabilitas.

Berdasarkan hasil penelitian terdahulu yang menunjukkan hasil tidak konsisten, maka dapat dikatakan bahwa nilai perusahaan dipengaruhi oleh berbagai macam faktor. Perumusan masalah antara lain apakah kebijakan dividen, ukuran perusahaan, struktur modal, likuiditas, dan profitabilitas berpengaruh terhadap nilai perusahaan?. Selanjutnya, penelitian ini diharapkan dapat bermanfaat untuk menjadi acuan bagi manajer dalam mengambil kebijakan terkait nilai perusahaan, menjadi bahan evaluasi bagi perusahaan agar dapat mengetahui faktor-faktor apa saja yang dapat meningkatkan nilai perusahaan, serta dapat menjadi bahan pertimbangan bagi investor dan calon investor dalam menanamkan modalnya pada perusahaaan yang tepat.

\section{LANDASAN TEORI}

2.1 Teori Sinyal atau Signalling Theory

Sinyal merupakan suatu tindakan yang diambil oleh perusahaan untuk memberi rambu-rambu kepada para investor tentang bagaimana manajemen melihat prospek perusahaan dimasa mendatang (Brigham \& Houston, 2006). Dengan adanya sinyal tersebut, investor akan dapat mengambil keputusan untuk menanamkan modalnya atau tidak. Jika sinyal yang diberikan baik maka investor akan cenderung menginvestasikan modalnya pada perusahaan sehingga harga saham akan tinggi dan nilai perusahaan akan meningkat.

\subsection{Nilai Perusahaan}

(Setyani, 2018 ) menerangkan nilai perusahaan sebagai suatu kondisi pencapaian perusahan atas kepercayaan 
masyarakat terhadap perusahaan sejak perusahaan tersebut didirikan sampai dengan saat ini. Nilai perusahan tercermin pada harga sahamnya, dimana tingginya harga saham meningkatkan nilai perusahaan.

\subsection{Kebijakan Dividen}

(Sartono, 2010) mendefinisikan kebijakan dividen sebagai suatu keputusan apakah laba yang diperoleh perusahaan akan dibagikan kepada pemegang saham atau akan ditahan guna untuk investasi dimasa mendatang. Semakin besar dividen yang dibagikan maka harga saham cenderung tinggi sehingga investor tertarik untuk berinvestasi dan nilai perusahaan akan meningkat.

\subsection{Ukuran Perusahaan}

Ukuran perusahaan merupakan besar kecilnya suatu perusahaan yang ditunjukkan oleh total aktiva perusahaan. Perusahaan besar akan lebih mudah mengakses ke pasar modal karena perusahaan besar lebih fleksibel untuk mendapatkan dana (Riny, 2018). Dalam menanamkan modalnya, investor akan mempertimbangkan ukuran perusahaan, karena ukuranperusahaan yang besar dianggap telah berkembang dan memiliki kinerja yang baik (Putra \& Lestari, 2016).

\subsection{Struktur Modal}

Struktur modal merupakan perbandingan antara hutang jangka panjang dengan modal sendiri (Riyanto, 2001). Perusahaan dengan tingkat pengembangan usaha yang besar membutuhkan tambahan dana dari pihak eksternal untuk mengembangkan usahanya. Dimana perusahaan dengan tingkat pengembangan usaha yang baik dalam jangka panjang akan memberikan keuntungan besar kepada investor, sehingga berpengaruh pada peningkatan nilai perusahaan (Dhani \& Utama, 2017).

\subsection{Likuiditas}

(Chasanah, 2018) menerangkan likuiditas sebagai kemampuan perusahaan dalam memenuhi kewajiban jangka pendeknya. Perusahaan dengan likuiditas yang baik dianggap mempunyai kinerja yang baik pula. Semakin tinggi likuiditas maka kemampuan perusahaan dalam memenuhi kewajiban lancarnya semakin baik. Tingginya likuiditas akan meningkatkan nilai perusahaan (Riny, 2018).

\subsection{Profitabilitas}

(Riyanto, 2001) mendefinisikan profitabilitas sebagai kemampuan perusahaan dalam memperoleh laba selama periode tertentu. Untuk dapat melangsungkan kegiatan operasinya, perusahaan harus berada dalam keadaan yang menguntungkan. Investor akan tertarik dengan perusahaan yang memiliki tingkat profitabilitas tinggi. Sehingga, profitabilitas dapat mempengaruhi nilai perusahaan (Setyani, 2018 ).

\subsection{Penelitian Sebelumnya}

Penelitian (Warouw, Nangoy, \& Saerang, 2016) menyatakan hasil secara parsial nilai perusahaan tidak dipengaruhi oleh perputaran modal kerja dan profitabilitas.

Penelitian (Dhani \& Utama, 2017) membuktikan pertumbuhan perusahaan dan struktur modal tidak berpengaruh terhadap nilai perusahaan. Sedangkan profitabilitas berpengaruh terhadap nilai perusahaan.

Penelitian (Lumoly, Murni, \& Untu, 2018) menunjukkan hasil bahwa nilai perusahaan (PBV) tidak dipengaruhi oleh likuiditas (CR) dan ukuran perusahaan (Size). Sedangkan profitabilitas (ROE) memiliki pengaruh terhadap nilai perusahaan (PBV).

Penelitian (Wijoyo, 2018) menyimpulkan profitabilitas memiliki pengaruh yang signifikan terhadap nilai perusahaan. Sedangkan struktur aset, 
kebijakan hutang, dan kebijakan deviden tidak mempunyai pengaruh yang signifikan terhadap nilai perusahaan.

Penelitian (Gunawan, Pituringsih, \& Widyastuti, 2018) menunjukkan hasil struktur modal, kebijakan dividen, ukuran perusahaan, profitabilitas, dan likuiditas secara parsial berpengaruh positif dan signifikan terhadap nilai perusahaan.

\subsection{Kerangka Pemikiran}

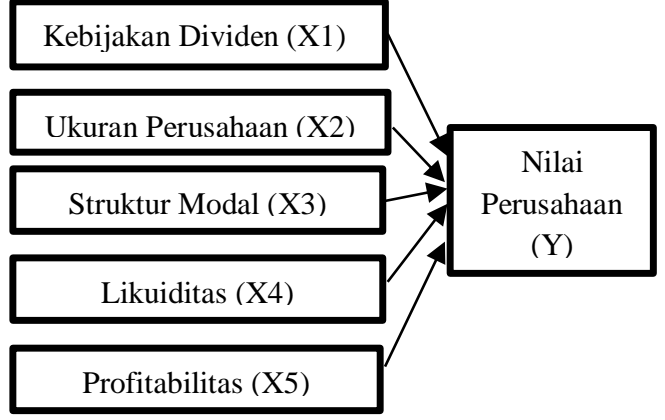

Gambar 1. Kerangka Pemikiran

\subsection{Hipotesis Penelitian Pengaruh Kebijakan Dividen Terhadap Nilai Perusahaan}

Menurut penelitian (Putra \& Lestari, 2016) mengemukakan bahwa kebijakan dividen berpengaruh terhadap nilai perusahaan. Hasil penelitian tersebut konsisten dengan penelitian yang dilakukan oleh (Gunawan, Pituringsih, \& Widyastuti, 2018) dan (Umam \& Hartono, 2019).

H1: Kebijakan Dividen berpengaruh terhadap Nilai Perusahaan

\subsection{Pengaruh Ukuran Perusahaan Terhadap Nilai Perusahaan \\ Menurut penelitian (Umam \&} Hartono, 2019) mengemukakan bahwa ukuran perusahaan berpengaruh terhadap nilai perusahaan. Hasil penelitian tersebut konsisten dengan penelitian yang dilakukan oleh (Gunawan, Pituringsih, \& Widyastuti, 2018).

H2: Ukuran Perusahaan berpengaruh terhadap Nilai Perusahaan

\subsection{Pengaruh Struktur Modal Terhadap Nilai Perusahaan \\ Menurut penelitian (Abidin,} Yusniar, \& Ziyad, 2014) mengemukakan bahwa struktur modal berpengaruh terhadap nilai perusahaan. Hasil penelitian ini sejalan dengan penelitian yang dilakukan oleh (Chasanah \& Adhi, 2017) dan (Gunawan, Pituringsih, \& Widyastuti, 2018).

H3: Struktur Modal berpengaruh terhadap Nilai Perusahaan

\subsection{Pengaruh Likuiditas Terhadap Nilai Perusahaaan}

Menurut penelitian (Andriani \& Rudianto, 2019) menyatakan bahwa likuiditas berpengaruh terhadap nilai perusahaan. Hasil penelitian ini didukung oleh penelitian yang dilakukan oleh (Gunawan, Pituringsih, \& Widyastuti, 2018).

H4: Likuiditas berpengaruh terhadap Nilai Perusahaan

\subsection{Pengaruh Profitabilitas Terhadap Nilai Perusahaan \\ Menurut penelitian (Chasanah \&} Adhi, 2017) mengemukakan bahwa profitabilitas berpengaruh terhadap nilai perusahaan. Hasil penelitian ini didukung oleh penelitian yang dilakukan oleh (Gunawan, Pituringsih, \& Widyastuti, 2018), (Wijoyo, 2018), (Lumoly, Murni, \& Untu, 2018), dan (Dhani \& Utama, 2017).

H5: Profitabilitas berpengaruh terhadap Nilai Perusahaan

\section{METODE PENELITIAN}

Jenis penelitian termasuk penelitian kuantitatif. Sumber data menggunakan data sekunder, dengan instrumen penelitian berupa dokumentasi laporan keuangan. Populasinya adalah perusahaan manufaktur sektor industri barang konsumsi yang terdaftar di BEI periode 2016-2018. Berdasarkan teknik purposive 
sampling, diperoleh sampel sebanyak 18 perusahaan. Teknik analisis data menggunakan analisis regresi linier berganda.

Tabel 1.Variabel Penelitian dan pengukurannya

\begin{tabular}{|c|c|}
\hline Vo & oukui \\
\hline $\begin{array}{l}\text { Nilai } \\
\text { Perusahaan } \\
\text { (Y) }\end{array}$ & $\begin{array}{l}\mathrm{PBV}=\text { Harga perlembar } \\
\text { saham / Nilai buku } \\
\text { perlembar saham } \\
\text { (Chasanah \& Adhi, 2017) }\end{array}$ \\
\hline $\begin{array}{l}\text { Kebijakan } \\
\text { Dividen } \\
\text { (X1) }\end{array}$ & $\begin{array}{c}\mathrm{DPR}=\frac{\text { Dividen per share }}{\text { Earning per share }} \\
\quad(\text { Umam \& Hartono, } 2019)\end{array}$ \\
\hline $\begin{array}{l}\text { Ukuran } \\
\text { Perusahaan } \\
\text { (X2) }\end{array}$ & $\begin{array}{l}\text { SIZE }=\text { Ln (total aset }) \\
\quad(\text { Umam \& Hartono, 2019) }\end{array}$ \\
\hline $\begin{array}{l}\text { Struktur } \\
\text { Modal } \\
\text { (X3) }\end{array}$ & $\begin{array}{l}\text { DER }=\frac{\text { Total Debt }}{\text { Total Equity }} \\
\quad(\text { Chasanah \& Adhi, 2017) }\end{array}$ \\
\hline $\begin{array}{l}\text { Likuiditas } \\
\text { (X4) }\end{array}$ & 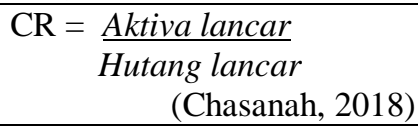 \\
\hline $\begin{array}{l}\text { Profitabilit } \\
\text { as (X5) }\end{array}$ & $\begin{aligned} \mathrm{ROA}= & \frac{\text { Laba }}{\text { Total aset }} \\
& \text { (Chasanah, 2018) }\end{aligned}$ \\
\hline
\end{tabular}

\section{HASIL DAN PEMBAHASAN}

\subsection{Deskripsi Umum Data Penelitian} Tabel 2.Pemilihan Sampel

\begin{tabular}{lll}
\hline No Kriteria & Jlh \\
\hline 1 Perusahaan Manufaktur & 40 \\
Sektor Industri Barang & \\
Konsumsi yang terdaftar di & \\
BEI secara berturut-turut & \\
selama periode 2016-2018. & \\
2 Perusahaan yang tidak & $(22)$ \\
menyampaikan laporan & \\
keuangan lengkap dan tidak & \\
membagikan dividen berturut- & \\
turut selama periode 2016- & \\
2018. & \\
3 Sampel penelitian & \\
4 Jumlah data yang digunakan & 54 \\
dalam peneltian & \\
(18 perusahaan x masa & \\
penelitian 3 tahun) & \\
5 Data Outlier & \\
\hline
\end{tabular}

6 Jumlah data penelitian yang 47 dapat diolah dalam penelitian

Sumber: Data diolah (2019)

\subsection{Hasil Penelitian}

4.2.1. Uji Asumsi Klasik

\subsubsection{Uji Normalitas (Kolmogorov-} Smirnov)

Uji normlitas dengan metode Kolmogorov-Smirnov, digunakan untuk menguji apakah nilai residul yang dihasilkan terdistribusi normal atau tidak. Residual terdistribusi normal apabila nilai signifikansi $>0,05$.

Tabel 3.Hasil Uji Normalitas

\begin{tabular}{ccc}
\hline Variabel Sig. & Standar & Keterangan \\
\hline $\left.\begin{array}{l}\text { Unstandardi } \\
\text { zed Residual }\end{array}\right), 200$ & $>0,05$ & $\begin{array}{c}\text { Data } \\
\text { Terdistribusi } \\
\text { Normal }\end{array}$ \\
\hline
\end{tabular}

Sumber: Data diolah (2019)

\subsubsection{Uji Multikolinieritas (Variance Inflation Factor)}

Tabel 4. Hasil Uji Multikolinieritas

\begin{tabular}{|c|c|c|c|c|c|c|}
\hline Var & Tolerance & Std. & VIF & Std & Keterangan \\
\hline DPR & 0,495 & $>0,10$ & 2,020 & $<10$ & $\begin{array}{c}\text { Tidak terjadi } \\
\text { multikolinearitas }\end{array}$ \\
\hline SIZE & 0,576 & $>0,10$ & 1,735 & $<10$ & $\begin{array}{c}\text { Tidak terjadi } \\
\text { multikolinearitas }\end{array}$ \\
\hline DER & 0,481 & $>0,10$ & 2,078 & $<10$ & $\begin{array}{c}\text { Tidak terjadi } \\
\text { multikolinearitas }\end{array}$ \\
\hline CR & 0,278 & $>0,10$ & 3,600 & $<10$ & $\begin{array}{c}\text { Tidak terjadi } \\
\text { multikolinearitas }\end{array}$ \\
\hline ROA & 0,286 & $>0,10$ & 3,499 & $<10$ & $\begin{array}{c}\text { Tidak terjadi } \\
\text { multikolinearitas }\end{array}$ \\
\hline
\end{tabular}

Sumber: Data diolah (2019)

Dari tabel 4, diketahui nilai

Tolerance $>0,10$ dan nilai VIF $<10$, maka dapat dinyatakan bahwa tidak terjadi multikolinieritas.

\subsubsection{Uji Autokorelasi (Durbin Watson)}

Tabel 5. Hasil Uji Autokorelasi

\begin{tabular}{cccccc}
\hline DW & dU & dL & 4-dU & 4-dL & Keterangan \\
\hline 2,14 & 1,773 & 1,307 & 2,22 & 2,69 & Tidak \\
1 & 6 & 3 & 64 & 27 & Autokorela
\end{tabular}

si

Sumber: Data diolah (2019) 
Dari tabel 5, dapat diketahui nilai Durbin Watson sebesar 2,141 yang terletak diantara dU dan 4-dU (1,7736 < $2,141<2,2264)$. Maka disimpulkan bahwa tidak terjadi autokorelasi.

\begin{tabular}{|c|c|c|c|}
\hline 2.1 & $\begin{array}{l}\text { 4. Uji } \\
\text { (Spea } \\
\text { bel } 6 . \mathrm{Hz}\end{array}$ & $\begin{array}{l}\text { F } \\
\text { Irman's } \\
\text { asil Uji } \mathrm{H}\end{array}$ & $\begin{array}{l}\text { teroskedastisitas } \\
\text { p) } \\
\text { eroskedastisitas }\end{array}$ \\
\hline Vari & $\begin{array}{l}\text { Sig. } \\
(2- \\
\text { tailed) }\end{array}$ & Standar & Keterangan \\
\hline DPR & 0,526 & $>0,05$ & $\begin{array}{c}\text { Tidak Terjadi } \\
\text { Heteroskedastisitas }\end{array}$ \\
\hline SIZE & 0,985 & $>0.05$ & $\begin{array}{c}\text { Tidak Terjadi } \\
\text { Heteroskedastisitas }\end{array}$ \\
\hline DER & 0,731 & $>0,05$ & $\begin{array}{c}\text { Tidak Terjadi } \\
\text { Heteroskedastisitas }\end{array}$ \\
\hline CR & 0,344 & $>0,05$ & $\begin{array}{c}\text { Tidak Terjadi } \\
\text { Heteroskedastisitas }\end{array}$ \\
\hline $\mathrm{OA}$ & 0,405 & $>0,05$ & $\begin{array}{c}\text { Tidak Terjadi } \\
\text { Heteroskedastisitas }\end{array}$ \\
\hline
\end{tabular}

Sumber: Data diolah (2019)

Pengujian heteroskedastisitas menggunakan metode Spearman's rho. Dari tabel 6 diketahui nilai Sig. (2-tailed) masing-masing variabel > 0,05. Maka dapat disimpulkan bahwa tidak terjadi heteroskedastisitas.

\subsubsection{Uji Regresi Linier Berganda} 4.2.2.1. Model Regresi

Tabel 7. Model Regresi

\begin{tabular}{lr}
\hline \multicolumn{1}{c}{ Model } & \multicolumn{1}{c}{ B } \\
\hline (Constant) & $-7,645$ \\
DPR & $-3,190$ \\
SIZE & 0,268 \\
DER & 1,579 \\
CR & $-0,293$ \\
ROA & 45,241 \\
\hline \multicolumn{2}{c}{ Sumber: Data diolah (2019) }
\end{tabular}

$\mathrm{Y}=-7,645-3,190 \mathrm{DPR}+0,268$ SIZE + 1,579DER $-0,293 \mathrm{CR}+45,241 \mathrm{ROA}$

Persamaan diatas dapat dijelaskan sebagai berikut:
1) Nilai konstanta untuk variabel nilai perusahaan sebesar $-7,645$, dapat diartikan jika semua variabel independen sama dengan nol, maka nilai perusahaan bernilai sebesar 7,645 .

2) Nilai koefisien regresi variabel kebijakan dividen sebesar $-3,190$, dapat diartikan bahwa setiap peningkatan kebijakan dividen sebesar 1 persen maka akan menurunkan nilai perusahaan sebesar 3,190 dengan asumsi variabel lain tetap.

3) Nilai koefisien regresi variabel ukuran perusahaan sebesar 0,268, dapat diartikan bahwa setiap peningkatan ukuran perusahaan sebesar 1 persen maka akan meningkatkan nilai perusahaan sebesar 0,268 dengan asumsi variabel lain tetap.

4) Nilai koefisien regresi variabel struktur modal sebesar 1,579, dapat diartikan bahwa setiap peningkatan struktur modal sebesar 1 persen maka akan meningkatkan nilai perusahaan sebesar 1,579 dengan asumsi variabel lain tetap.

5) Nilai koefisien regresi variabel likuiditas sebesar -0,293, dapat diartikan bahwa setiap peningkatan likuiditas sebesar 1 persen maka akan menurunkan nilai perusahaan sebesar 0,293 dengan asumsi variabel lain tetap.

6) Nilai koefisien regresi variabel profitabilitas sebesar 45,241, dapat diartikan bahwa setiap peningkatan profitabilitas sebesar 1 persen maka akan meningkatkan nilai perusahan sebesar 45,241 dengan asumsi variabel lain tetap.

\subsubsection{Uji Kelayakan Model} Tabel 8.Hasil Uji F-Statistik

\begin{tabular}{|c|c|c|}
\hline $\begin{array}{c}\text { Keterang } \\
\mathrm{n} \\
\end{array}$ & $F_{\text {hitung }} F_{\text {tabel }}$ & $\begin{array}{c}\text { Sig }_{\text {hitu }} \\
\text { ng Sig. Hasil }\end{array}$ \\
\hline Uji F & $\begin{array}{cc}21,69 & >2,4 \\
3 & 43\end{array}$ & $\begin{array}{c}0,000 \quad<0,0 \text { Model } \\
5 \quad \text { Layak }\end{array}$ \\
\hline
\end{tabular}

Sumber: Data diolah (2019) 
Dari tabel 8, dapat diketahui $F_{\text {hitung }}$ $>\mathrm{F}_{\text {tabel }}(21,693>2,443)$ dan Signifikansi $<0,05(0,000<0,05)$, maka Ho ditolak. Sehingga dapat disimpulkan bahwa Kebijakan Dividen, Ukuran Perusahaan, Struktur Modal, Likuiditas, dan Profitabilitas secara simultan mempengaruhi Nilai Perusahaan.

\subsubsection{Uji Hipotesis (Uji t)}

Tabel 9.Hasil Uji Hipotesis

\begin{tabular}{|c|c|c|c|}
\hline $\begin{array}{c}\text { Hipotes } \\
\text { is }\end{array}$ & $t_{\text {hitung }} \quad t_{\text {tabel }}$ Sig. & Std. & $\begin{array}{c}\text { Keteran } \\
\text { gan }\end{array}$ \\
\hline & $-0,01$ & $<0,0$ & Diterim \\
\hline HI & $2,4732,020$ & 5 & $\mathrm{a}$ \\
\hline $\mathrm{H} 2$ & $1,3912,020^{0,17}$ & $\begin{array}{l}<0,0 \\
5\end{array}$ & Ditolak \\
\hline $\mathrm{H} 3$ & $\begin{array}{r}2,262 \\
2,020^{0,02}\end{array}$ & $\begin{array}{l}<0,0 \\
5\end{array}$ & $\begin{array}{c}\text { Diterim } \\
\mathrm{a}\end{array}$ \\
\hline $\mathrm{H} 4$ & $\begin{array}{rr}- & -0,14 \\
1,481 & 2,020\end{array}$ & $\begin{array}{c}<0,0 \\
5\end{array}$ & Ditolak \\
\hline H5 & $\begin{array}{l}7,833 \text { 2, } 020 \quad 00 \\
0\end{array}$ & $\begin{array}{c}<0,0 \\
5\end{array}$ & $\begin{array}{c}\text { Diterim } \\
\mathrm{a}\end{array}$ \\
\hline
\end{tabular}

Sumber: Data diolah (2019)

Berdasarkan tabel 9, jika nilai thitung $>t_{\text {tabel }}$ dan Signifikansi $<0,05$, maka dapat disimpulkan bahwa variabel independen secara parsial berpengaruh terhadap variabel dependen.

\subsubsection{Uji Koefisien Determinasi $\left(\mathbf{R}^{\mathbf{2}}\right)$} Tabel 10.Hasil Uji Koefisien Determinasi $\left(\mathrm{R}^{2}\right)$

\begin{tabular}{ccc}
\hline Model & $\begin{array}{c}\text { Adjusted R } \\
\text { Square }\end{array}$ & Keterangan \\
\hline 1 & 0,692 & $\begin{array}{c}\text { Berpengaruh } \\
69,2 \%\end{array}$ \\
\hline
\end{tabular}

Sumber: Data diolah (2019)

Dari tabel 10 diatas, diketahui nilai Adjusted R Square sebesar 0,692. Artinya pengaruh variabel Kebijakan Dividen, Ukuran Perusahaan, Struktur Modal, Likuiditas, dan Profitabilitas terhadap Nilai Perusahaan sebesar $69,2 \%$, sedangkan sisanya $30,8 \%$ dipengaruhi oleh variabel lain yang tidak dimasukkan dalam penelitian ini.

\subsection{Pembahasan}

Berdasarkan hasil pengujian pada tabel 9, dapat disimpulkan bahwa hipotesis pertama, kebijakan dividen berpengaruh terhadap nilai perusahaan. Hasil ini sejalan dengan (Putra \& Lestari, 2016). Hal ini menunjukkan semakin besar dividen yang dibagikan kepada investor maka akan meningkatkan nilai perusahaan. Semakin besar dividen yang dibagikan kepada investor menunjukkan bahwa perusahaan mempunyai kinerja yang baik. Sehingga investor akan menganggapnya sebagai sinyal yang baik yang kemudian akan meningkatkan harga saham, tingginya harga saham dapat meningkatkan nilai perusahaan.

Hipotesis kedua, ukuran perusahaan tidak berpengaruh terhadap nilai perusahaan. Hasil ini sejalan dengan (Suryandani, 2018). Hal ini berarti besar kecilnya perusahaan tidak dapat dijadikan tolak ukur dalam peningkatan nilai perusahaan. Dalam berinvestasi para investor tidak melihat seberapa besar ukuran perusahaan tersebut.

Hipotesis ketiga, struktur modal berpengaruh terhadap nilaiperusahaan. Hasil ini sejalan dengan (Abidin, Yusniar, \& Ziyad, 2014). Hal ini menunjukkan bahwa dengan adanya hutang perusahaan yang besar maka dapat meningkatkan nilai perusahaaan. Dengan adanya hutang yang besar manajemen diharapkan dapat mengoptimalkan hutang untuk membiayai kegiatan operasionalnya dengan baik, agar dapat memperoleh laba yang besar pula. Sehingga nilai perusahaan akan meningkat.

Hipotesis keempat, likuiditas tidak berpengaruh terhadap nilai perusahaan. Hasil ini sejalan penelitian (Chasanah, 2018). Hal ini berarti dalam menginvestasikan dananya investor tidak melihat seberapa besar kemampuan perusahaan dalam membayarkan utang lancarnya yang sudah jatuh tempo. Sehingga nilai perusahaan tidak dipengaruhi oleh besarnya likuiditas. 
Hipotesis kelima, profitabilitas berpengaruh terhadap nilai perusahaan. Hasil ini sejalan dengan (Chasanah \& Adhi, 2017). Hal ini berarti besarnya laba yang diperoleh perusahaan dalam menjalankan kegiatan operasionalnya dapat meningkatkan nilai perusahaan. Perolehan laba yang besar menunjukkan bahwa perusahaan memiliki kinerja yang baik dan memberikan sinyal bahwa perusahaan memiliki prospek yang baik dimasa mendatang, yang kemudian akan meningkatkan harga saham dan nilai perusahaan.

\section{KESIMPULAN DAN SARAN}

Berdasarkan hasil penelitian dan pembahasan yang telah dikemukakan diatas, maka dapat disimpulkan bahwa: (1) secara parsial kebijakan dividen, struktur modal, dan profitabilitas berpengaruh terhadap nilai perusahaan, sedangkan ukuran perusahaan dan likuiditas tidak berpengaruh terhadap nilai perusahaan, (2) secara simultan kebijakan dividen, ukuran perusahaan, struktur modal, likuiditas, dan profitabilitas berpengaruh terhadap nilai perusahaan, (3) pengaruh variabel kebijakan dividen, ukuran perusahaan, struktur modal, likuiditas, dan profitabilitas terhadap nilai perusahaan sebesar $69,2 \%$, sedangkan sisanya $30,8 \%$ dipengaruhi oleh variabel lain yang tidak dimasukkan dalam penelitian ini.

Keterbatasan dalam penelitian ini antara lain: 1) penelitian hanya mengambil sampel pada perusahaan manufaktur sektor industri barang konsumsi, 2) terbatasnya periode tahun penelitian serta variabel yang digunakan.

Saran bagi penelitian selanjutnya yaitu diharapkan dapat : 1) mengambil objek penelitian atau populasi pada seluruh perusahaan manufaktur yang terdaftar di Bursa Efek Indonesia, agar dapat digeneralisasikan pada sektor lain serta dapat dijadikan pedoman dan acuan yang lebih relevan, 2) menambah periode tahun penelitian serta menambah variabel lainnya untuk diuji pengaruhnya terhadap nilai perusahaan.

\section{DAFTAR PUSTAKA}

Abidin, Z., Yusniar, M. W., \& Ziyad, M. (2014). Pengaruh Struktur Modal, Kebijakan Dividen Dan Size Terhadap Nilai Perusahaan (Studi Pada Perusahaan Properti Di Bursa Efek Indonesia). Jurnal Wawasan Manajemen, Vol. 2, Nomor 3, 91-102.

Andriani, P. R., \& Rudianto, D. (2019). Pengaruh Tingkat Likuiditas, Profitabilitas, Dan Leverage Terhadap Nilai Perusahaan Pada Subsektor Makanan Dan Minuman Yang Tercatat Di Bei (Bei) Periode 2010-2017. Journal of Entrepreneurship, Management, and Industry (JEMI), 48-60.

Brigham, E. F., \& Houston. (2006). Dasar-Dasar Manajemen Keuangan. Edisi 10. Jakarta: Salemba Empat.

Brigham, E. F., \& Houston, J. F. (2010). Dasar-dasar Manajemen Keuangan (10th ed.). Jakarta: Salemba Empat.

Chasanah, A. N. (2018). Pengaruh Rasio Likuiditas, Profitabilitas, Struktur Modal Dan Ukuran Perusahaan Terhadap Nilai Perusahaan Pada Perusahaan Manufaktur Yang Terdaftar Di Bei Tahun 20152017. Jurnal Penelitian Ekonomi dan Bisnis, 39-47.

Chasanah, A. N., \& Adhi, D. K. (2017). Profitabilitas, Struktur Modal, Dan Likuiditas Pengaruhnya Terhadap Nilai Perusahaan Pada Perusahaan Real Estate Yang Listed Di Bei Tahun 2012-2015. Fokus Ekonomi, 129-146. 
Dhani, I. P., \& Utama, A. S. (2017). Pengaruh Pertumbuhan Perusahaan, Struktur Modal, Dan Profitabilitas Terhadap Nilai Perusahaan. Jurnal Riset Akuntansi dan Bisnis Airlangga Vol. 2. No. 1 , 135-148.

Gunawan, I. A., Pituringsih, E., \& Widyastuti, E. (2018). The Effect Of Capital Structure, Dividend Policy, Company Size, Profitability And Liquidity On Company Value (Study At Manufacturing Companies Listed On Indonesia Stock Exchange 2014-2016) . International Journal of Economics, Commerce and Management , 405-422.

Lumoly, S., Murni, S., \& Untu, V. N. (2018). Pengaruh Likuiditas, Ukuran Perusahaan Dan Profitabilitas Terhadap Nilai Perusahaan (Studi pada Perusahaan Logam dan Sejenisnya yang Terdaftar di Bursa Efek Indonesia). Jurnal EMBA Vol.6 No.3, 1108 - 1117.

Novari, P. M., \& Lestari, P. V. (2016). Pengaruh Ukuran Perusahaan, Leverage, Dan Profitabilitas Terhadap Nilai Perusahaan Pada Sektor Properti Dan Real Estate. E-Jurnal Manajemen Unud, Vol. 5, No.9, 5671-5694.

Putra, A. D., \& Lestari, P. V. (2016). Pengaruh Kebijakan Dividen, Likuiditas, Profitabilitas, Dan Ukuran Perusahaan Terhadap Nilai Perusahaan. E-Jurnal Manajemen Unud, 4044-4070.

Riny. (2018). Analisis Faktor-Faktor Yang Mempengaruhi Nilai Perusahaan Pada Perusahaan Consumer Goods Yang Terdaftar Di Bursa Efek Indonesia. JWEM STIE MIKROSKIL, Volume 8, Nomor 02, 139-150.

Riyanto, B. (2001). Dasar-Dasar Pembelanjaan Perusahaan. Edisi
Keempat. Cetakan Ketujuh. Yogyakarta: BPFE.

Sartono, R. A. (2010). Manajemen Keuangan Teori dan Aplikasi (4. ed.). Yogyakarta: BPFE.

Setyani, A. Y. (2018 ). Pengaruh Kebijakan Hutang, Kebijakan Dividen, Dan Profitabilitas Terhadap Nilai Perusahaan. JRAK, Volume 14, No 1, 15-24.

Sudana, I. M. (2011). Manajemen Keuangan Perusahaan. Jakarta: Erlangga.

Suryandani, A. (2018). Pengaruh Pertumbuhan Perusahaan, Ukuran Perusahaan, Dan Keputusan Investasi Terhadap Nilai Perusahaan Pada Perusahaan Sektor Property Dan Real Estate. Business Management Analysis Journal (BMAJ), Vol. 1 No. 1, 49-59.

Umam, A. C., \& Hartono, U. (2019). Firm Size, Profitabilitas, Struktur Modal, Kebijakan Dividen, Gcg, Csr, Dan Nilai Perusahaan (Studi Pada Perusahaan Sektor Finance Di Bursa Efek Indonesia). Jurnal Ilmu Manajemen Volume 7 Nomor 3 - Jurusan Manajemen Fakultas Ekonomi Universitas Negeri Surabaya, 642-654.

Warouw, C., Nangoy, S., \& Saerang, I. S. (2016). Pengaruh Perputaran Modal Kerja Dan Profitabilitas Terhadap Nilai Perusahaan Pada Perusahaan Farmasi Di Bursa Efek Indonesia. Jurnal Berkala Ilmiah Efisiensi, Volume 16 No. 02, 366-375.

Wijoyo, A. (2018). Faktor-Faktor Yang Mempengaruhi Nilai Perusahaan Pada Perusahaan Property Dan Real Estate Di Bursa Efek Indonesia. Jurnal Ekonomi, 4861. 